\title{
Efficacy of Olanzapine-Triple Antiemetic Regimen in Patients with Gastrointestinal Tumor and High Risk of Chemotherapy-Induced Nausea and Vomiting Receiving Moderately Emetogenic Chemotherapy: A Retrospective Study
}

This article was published in the following Dove Press journal: Cancer Management and Research

\author{
Xuan $W u\left(D^{1-3, *}\right.$ \\ Jingxun $\mathrm{Wu}^{4, *}$ \\ Gangling Tong ${ }^{1-3, *}$ \\ Boran Cheng (iD) ${ }^{1-3, *}$ \\ Minhua Chen ${ }^{5, *}$ \\ Shaokang $\mathrm{Yu}^{\mathrm{I}-3}$ \\ Lirui $\mathrm{He}^{6}$ \\ Zhu $\mathrm{Li}^{1-3}$ \\ Shubin Wang ${ }^{1-3}$ \\ 'Department of Oncology, Peking University \\ Shenzhen Hospital, Shenzhen 518036, \\ People's Republic of China; ${ }^{2}$ Shenzhen Key \\ Laboratory of Gastrointestinal Cancer \\ Translational Research, Shenzhen 518036, \\ People's Republic of China; ${ }^{3}$ Cancer Institute \\ of Shenzhen-PKU-HKUST Medical Center, \\ Shenzhen 518036, People's Republic of \\ China; ${ }^{4}$ Department of Medical Oncology, \\ The First Affiliated Hospital of Xiamen \\ University, Xiamen 36I003, People's \\ Republic of China; ${ }^{5}$ Community Healthcare \\ Center, Shenzhen Traditional Chinese \\ Medicine Hospital, Shenzhen 518033, \\ People's Republic of China; ${ }^{6}$ Department of \\ Gastrointestinal Surgery, Peking University \\ Shenzhen Hospital, Shenzhen 5I8036, \\ People's Republic of China
}

*These authors contributed equally to this work

Correspondence: Shubin Wang Department of Medical Oncology Peking University Shenzhen Hospital,

I I 20 Lianhua Road, Shenzhen 518036,

People's Republic of China

Tel +8675683923333

Fax +8675683061340

Email shubinwang2013@I63.com
Purpose: Dexamethasone combined with 5-hydroxytryptamine type 3 receptor antagonists (5-HT3 RA) dual regimen is the standard prophylaxis regimen for patients receiving moderately emetogenic chemotherapy (MEC). However, it has been found in real-world practice that chemotherapy-induced nausea and vomiting (CINV) remains poorly controlled among patients with gastrointestinal tumor, especially in those with high-risk factors for vomiting, such as female, young, and non-alcoholic individuals. Hence, we aimed to evaluate the efficacy of an olanzapine-containing triple regimen in this clinical setting.

Patients and Methods: We retrospectively reviewed the clinical records of gastrointestinal tumor patients who received mFOLFOX6, XELOX, or FOLFIRI chemotherapy at two institutions. All patients included were female and less than 55 years old, with no history of drinking. The patients were divided into two groups for olanzapine-containing triple therapy (olanzapine, tropisetron, and dexamethasone) and non-olanzapine dual therapy (tropisetron and dexamethasone). The study outcomes were complete response (CR), complete control (CC), nausea control, and quality of life (QoL) by the functional living index-emesis (FLIE) questionnaire.

Results: A total of 93 patients were included in the study (olanzapine: 40; control: 53). The $\mathrm{CR}$ rate in the olanzapine group was significantly higher than that in the control group in delayed and overall phase ( $75.0 \%$ vs $54.7 \%, \mathrm{p}=0.044 ; 70.0 \%$ vs $47.2 \%$; $=0.028$ ). The CC rate in the overall phase was also better in the olanzapine group ( $62.5 \%$ vs $39.6 \%, \mathrm{p}=0.029)$. The control of nausea in the overall phase showed a superior trend in the olanzapine group $(p=0.059)$. The olanzapine group exhibited higher FLIE scores, which demonstrated better QoL. More patients in the olanzapine group exhibited somnolence and dizziness. Conversely, the incidence of insomnia and anorexia in the olanzapine group was lower.

Conclusion: This retrospective study indicates that in gastrointestinal tumor patients with high-risk factors for CINV who were receiving MEC, olanzapine-containing triple antiemetic regimen exhibit better efficacy and QoL as compared to non-olanzapine dual regimen. Further randomized studies are required to confirm these results.

Keywords: CINV, MEC, olanzapine, gastrointestinal tumor, high risk of emesis

\section{Introduction}

Chemotherapy-induced nausea and vomiting (CINV) is the most common side effect of anti-tumor treatment with cytotoxic drugs. According to statistics, in the 
absence of appropriate antiemetic prophylaxis, the incidence of CINV is as high as $70 \%$ to $85 \%$. ${ }^{1}$ Poorly controlled CINV can lead to serious clinical symptoms such as dehydration, electrolyte imbalance, and malnutrition, producing detrimental effects on treatment outcomes. ${ }^{2-4}$

The frequency and extent of CINV are influenced by various factors such as the type and dosage of anticancer drugs, treatment plans, routes of administration, and personal characteristics (for example, gender, age, previous chemotherapy response, and alcohol consumption history). ${ }^{5,6}$ In recent years, with the emergence of 5-hydroxytryptamine 3 receptor antagonists (5-HT3 RA) and neurokinin-1 receptor antagonists (NK1 RA), CINV occurrence has been significantly controlled, and guidelines recommend the use of a combination of these drugs to prevent CINV in patients with carboplatinbased moderately emetogenic chemotherapy (MEC) or highly emetogenic chemotherapy (HEC). ${ }^{7-9}$ For the prophylaxis of acute CINV resulting from non-carboplatin MEC regimens, American Society of Clinical Oncology (ASCO) and Multinational Association for Supportive Care in Cancer/ European Society for Medical Oncology (MASCC/ESMO) recommend a two-drug antiemetic regimen consisting of a 5-HT3 RA and dexamethasone. ${ }^{10,11}$ However, even with standard prophylaxis, some patients may experience nausea and vomiting, especially for those receiving MEC. In gastrointestinal tumors, the mFOLFOX, XELOX, or FOLFIRI regimen consisting of irinotecan, oxaliplatin, capecitabine and fluorouracil (5-FU) is the most common chemotherapy regimen and is classified as a MEC. Studies have shown that patients taking the FOLFIRI regimen have a vomiting rate of up to $50 \%$, while for the FOLFOX6 regimen, the rate is up to $42 \%{ }^{12}$ In the real-world practice, we observed that the proportion of vomiting is still high for patients with high-risk factors for CINV, such as female, young, and non-alcoholic individuals, while being treated with a dual regimen of dexamethasone and 5-HT3 RA for prophylaxis.

Olanzapine is an atypical antipsychotic agent that has been widely used in the treatment of schizophrenia and refractory depression. It blocks multiple neurotransmitter receptors, including dopamine (D1, D2, D3, and D4), serotonin (5-HT2A, 5-HT2C, 5-HT3, and 5-HT6), multiple muscarinic, alpha-1 adrenergic and histaminic H1 receptors. ${ }^{13,14}$ In particular, the various neuromodulating mechanisms of D2, 5-HT2, and 5-HT3 receptors provide a pharmacological basis for the prevention of CINV. A series of clinical trials have been conducted on the efficacy and safety of olanzapine for the prophylaxis and rescue of CINV. The use of olanzapine in combination with dexamethasone and 5-HT 3 RA has shown promising results in preventing CINV and/or breakthrough emesis. ${ }^{15-17}$ On the basis of the positive results, ASCO recommended addition of olanzapine to the backbone of a 5-HT3 RA, NK 1 RA, and dexamethasone for HEC. ${ }^{10}$ However, for patients receiving MEC, especially those with high-risk factors for vomiting, there is currently little research on the olanzapine triple regimen for CINV prevention.

Considering that in the two immigrant cities Shenzhen and Xiamen, South of China, patients with gastrointestinal tumor were relatively young and common among women, we observed more prevalence of CINV in clinical practice.

Therefore, this study intends to explore whether the addition of olanzapine can increase the efficacy of the current dual prophylaxis regimen of dexamethasone and 5-HT3 RA for gastrointestinal tumor patients with high emetogenic risk factors who are receiving MEC. Additionally, it aims to identify a more cost-effective antiemetic regimen for such patients.

\section{Patients and Methods Study Subjects}

From 2017, in order to improve CINV control, more than 20 hospitals in the south of China, including the two institutes Peking University Shenzhen Hospital and The First Affiliated Hospital of Xiamen University in this study, have carried out a project called non-emesis ward. The project allowed a more comprehensive assessment of the CINV risk for each patient. Meanwhile, physician in charge can choose whether or not to use additional antiemetic agents according to the individual risk of developing CINV and the clinical experience. The study evaluated patients who underwent chemotherapy between 2017 and 2019, at the Department of Medical Oncology in the two institutions. The retrospective data collection of this study was approved by the ethics committee of both hospitals and followed the Declaration of Helsinki.

\section{Inclusion Criteria}

Patients pathologically confirmed with gastrointestinal tumors; patients who received an initial FOLFOX (oxaliplatin +5 -FU/calcium leucovorin), FOLFIRI (irinotecan + 5-FU/calcium leucovorin) or XELOX (oxaliplatin + capecitabine) regimen; female; age at the time of chemotherapy administration between 18 and 55 years; no long-term or excessive alcohol intake history (alcohol intake $<5$ times per week or $<100 \mathrm{~g}$ per day); performance status ECOG $0-1$; adequate haematological, hepatic, renal and 
metabolic function parameters; patients received olanzapine plus tropisetron and dexamethasone triple regimen or only tropisetron and dexamethasone dual regimen for antiemetic prophylaxis.

\section{Exclusion Criteria}

Patients with non-chemotherapy-related nausea or vomiting (eg, gastrointestinal tract obstruction, ascites effusion requiring paracentesis, brain metastasis or other brain tumors/lesions); those inability to receive standard-dose of dexamethasone due to uncontrollable diabetes or gastrointestinal hemorrhage, etc.; patients being treated with another antipsychotic agent or NK1 receptor antagonists; patients with severe underlying disorders such as severe heart disease, liver and kidney disease; those with incomplete medical records, patient diaries or FLIE scale.

\section{Methods}

\section{Treatments}

\section{Chemotherapy}

A. mFOLFOX6 regimen: oxaliplatin $85 \mathrm{mg} / \mathrm{m}^{2}$, intravenous infusion for $2 \mathrm{~h}$, followed by calcium leucovorin (LV) $400 \mathrm{mg} / \mathrm{m}^{2}$, intravenous infusion for $2 \mathrm{~h}$ on day 1 , and then $5-\mathrm{FU} 400 \mathrm{mg} / \mathrm{m}^{2}$, intravenous bolus injection, followed by 5 -FU $2400-3000 \mathrm{mg} / \mathrm{m}^{2}$, continuous infusion for $46 \mathrm{~h}$, every 2 weeks.

B. FOLFIRI regimen: irinotecan $180 \mathrm{mg} / \mathrm{m}^{2}$, intravenous infusion for $2 \mathrm{~h}$, followed by LV $400 \mathrm{mg} / \mathrm{m}^{2}$, intravenous infusion for $2 \mathrm{~h}$ on day 1, and then 5 -FU $400 \mathrm{mg} /$ $\mathrm{m}^{2}$, intravenous bolus injection, followed by 5 -FU $2400-3000 \mathrm{mg} / \mathrm{m}^{2}$, continuous infusion for $46 \mathrm{~h}$, every 2 weeks.

C. XELOX regimen: oxaliplatin $130 \mathrm{mg} / \mathrm{m} 2$, intravenous infusion for $2 \mathrm{~h}$, capecitabine $1000 \mathrm{mg} / \mathrm{m} 2$ twice daily on days 1 through 14 , every 3 weeks.

\section{Prophylactic Antiemetic Therapy}

Olanzapine triple regimen (olanzapine group): dexamethasone (12 mg intravenous infusion, $\mathrm{d} 1 \sim 3$ ) and tropisetron (5 $\mathrm{mg}$ intravenous infusion, d1) and olanzapine $(5 \mathrm{mg}$ orally, $\mathrm{d} 1 \sim 3)$.

Non-Olanzapine dual regimen (control group): dexamethasone (12 $\mathrm{mg}$ intravenous infusion, $\mathrm{d} 1 \sim 3)$ and tropisetron (5 mg intravenous infusion, $\mathrm{d} 1$ ).

The choice of antiemetic prophylaxis was at the discretion of the treating physician.

\section{Efficacy Evaluation Criteria and Study \\ Endpoints}

This study only observed and evaluated nausea, vomiting, and drug-related adverse events (AEs) in patients after the first course of chemotherapy. According to the non-emesis ward project, patients have two or more of the CINV risk factors were asked for comprehensive evaluation of CINV before and after chemotherapy, including completion of a daily patient diary within $0 \sim 120 \mathrm{~h}$ after the first two cycles of chemotherapy describing their CINV experience, including the time, frequency, symptom assessments, related adverse and FLIE questionnaire. Risk factors include female, young, low alcohol intake history, any history of motion sickness or pregnancy-associated morning sickness, symptoms of anxiety or expectation. Regrettably, more than half of patients have failed to record sufficient detail of nausea time. The nausea and anorexia scores were based on the visual analog scale (VAS). The impact on the quality of life (QoL) was measured using the functional living index-emesis (FLIE) questionnaire on the 6th day of chemotherapy. Nausea and vomiting and adverse drug reactions were evaluated according to the Common Terminology Criteria for Adverse Events (CTC-AE) version 4.03.

The primary endpoint of this study was the complete response (CR) (no vomiting, no use of rescue medication) in the overall phase $(0-120 \mathrm{~h}$ post-chemotherapy). The secondary endpoints were $\mathrm{CR}$ in the acute phase (0-24 $\mathrm{h}$ post-chemotherapy) and delayed phase (24-120 h postchemotherapy); complete control (CC) (no vomiting, no use of rescue medication, and maximum nausea (VAS $<25 \mathrm{~mm}$ ); no nausea (VAS $<5 \mathrm{~mm}$ ) and no significant nausea (VAS $<25 \mathrm{~mm}$ )) in the overall phase; QoL assessed using the FLIE questionnaire; no impact on daily life defined as FLIE total score $>108$; adverse events related to antiemetic drugs in the two groups, such as constipation, insomnia, somnolence, dizziness, anorexia (VAS $<25 \mathrm{~mm}$ ), weight loss (weight decreased by $5 \%$ after chemotherapy), etc.

\section{Statistical Analysis}

Since this is a retrospective analysis, we did not perform a priori sample size calculation. However, Post hoc power analysis was conducted on existing datasets by G*Power 3.1 (developed by the Heinrich-Heine-University, Düsseldorf, Germany). The results revealed that the sample size in this study achieves a power higher than $80 \%$ with an effect size of 0.35 (two-sided $\alpha$ of 0.05 ). SPSS 16 software was used 
for data processing. Demographic and descriptive data were compared for the 2 groups (olanzapine versus control) using $t$-tests for continuous data, except where data were highly skewed and Wilcoxon rank-sum tests were used instead. Chi-square tests were used for categorical data when all expected cell counts were over 5; otherwise, the Fisher exact tests were used. The mean of the FLIE score between the groups was compared by $t$-test. The Chi-square test was used to analyze the $\mathrm{CR}$ rates, $\mathrm{CC}$ rates, no nausea rates and proportion of adverse events for group differences. Twosided $\mathrm{P}$ value $<0.05$ was considered statistically significant.

\section{Results}

\section{Clinical Characteristics}

A total of 93 patients were included in this study, with a median age of 45 years (range, 28-55 years). Of the patients, $40(43.0 \%)$ received the olanzapine triple regimen for antiemetic prophylaxis and $53(57.0 \%)$ received the nonolanzapine dual regimen. Figure 1 presents a flowchart of patient screening and selection for the study. Table 1 lists the demographic and clinical characteristics of the patients. Baseline and demographic characteristics were generally similar between the two groups. Most of the patients were diagnosed with colorectal cancer (78.5\%), and a small proportion of the patients was diagnosed with gastric cancer (21.5\%). Most patients receiving chemotherapy regimens including oxaliplatin (75.3\%).

\section{Efficacy}

Table 2 shows results for the primary endpoint. The olanzapine group had significantly higher $\mathrm{CR}$ rates in the delayed phase $(75.0 \%$ vs $54.7 \% ; \mathrm{p}=0.044)$ and overall phase $(70.0 \%$ vs $47.2 \% ; \mathrm{p}=0.028)$, compared with the control group. In the acute phase, there was no significant difference in $\mathrm{CR}$ rates between the two groups. (85.0\% vs $73.6 \% ; \mathrm{p}=0.309$ ) (Figure 2).

There was trend of improved nausea control in olanzapine group compared with the control, although this did not reach statistical significance (No nausea: $55.0 \%$ vs $35.8 \%, p=0.066$; No significant nausea: $65.0 \%$ vs $45.3 \%$, $\mathrm{p}=0.059$ ) (Table 3). The complete control rate of CINV was significantly better in the olanzapine group $(62.5 \%$ vs $39.6 \%, p=0.029$ ) (Figure 3).

\section{Quality of Life}

In terms of the FLIE scores for QoL, CINV did not impact the daily life in 30 patients $(75.0 \%)$ in the olanzapine group and in 26 patients (49.1\%) in the control group (Table 4). At the same time, the scores of FLIE were higher in the olanzapine group due to nausea domain, vomiting domain, or both (overall FLIE) (Figure 4).

\section{Adverse Events}

There was no serious treatment-related event in either group. All adverse events were grade 1 or grade 2. The

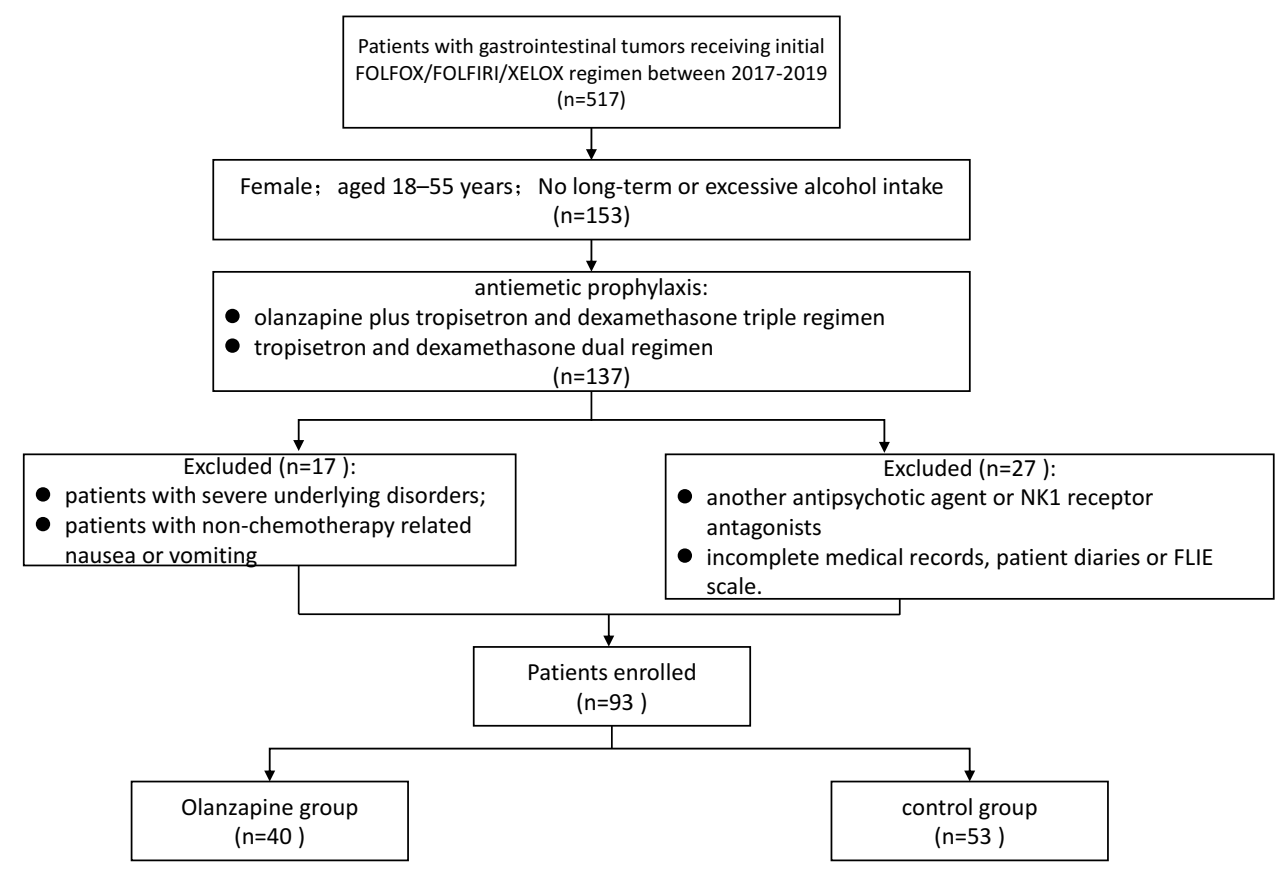

Figure I Patient screening and selection. 
Table I Baseline Demographic and Clinical Characteristics of the Study Patients

\begin{tabular}{|c|c|c|c|}
\hline Characteristics & $\begin{array}{l}\text { Olanzapine } \\
(n=40)\end{array}$ & $\begin{array}{l}\text { Control } \\
(n=53)\end{array}$ & P-value \\
\hline $\begin{array}{l}\text { Age }(y r) \\
\text { Median } \\
\text { Range }\end{array}$ & $\begin{array}{l}43 \\
28-54\end{array}$ & $\begin{array}{l}46 \\
29-55\end{array}$ & 0.162 \\
\hline $\begin{array}{l}\text { ECOG performance status } \\
0 \\
1\end{array}$ & $\begin{array}{l}13(32.5) \\
27(67.5)\end{array}$ & $\begin{array}{l}14(26.4) \\
39(73.6)\end{array}$ & 0.522 \\
\hline $\begin{array}{l}\text { Previous motion sickness } \\
\text { Yes } \\
\text { No }\end{array}$ & $\begin{array}{l}18(45.0) \\
22(55.0)\end{array}$ & $\begin{array}{l}23(43.4) \\
30(56.6)\end{array}$ & 0.877 \\
\hline $\begin{array}{l}\text { Previous vomiting of } \\
\text { pregnancy } \\
\text { Yes } \\
\text { No }\end{array}$ & $\begin{array}{l}25(62.5) \\
15(37.5)\end{array}$ & $\begin{array}{l}28(52.8) \\
25(47.2)\end{array}$ & 0.455 \\
\hline $\begin{array}{l}\text { Chemotherapy regimen } \\
\text { Oxaliplatin containing } \\
\text { Irinotecan containing }\end{array}$ & $\begin{array}{l}28(70.0) \\
12(30.0)\end{array}$ & $\begin{array}{l}42(79.2) \\
\text { II (20.8) }\end{array}$ & 0.306 \\
\hline $\begin{array}{l}\text { Purpose of chemotherapy } \\
\text { Neoadjuvant } \\
\text { Adjuvant } \\
\text { Palliative }\end{array}$ & $\begin{array}{l}6(15.0) \\
18(45.0) \\
16(40.0)\end{array}$ & $\begin{array}{l}6(11.3) \\
28(52.8) \\
19(35.8)\end{array}$ & 0.731 \\
\hline $\begin{array}{l}\text { Primary site of disease } \\
\text { Colorectal } \\
\text { Stomach }\end{array}$ & $\begin{array}{l}33(82.5) \\
7(17.5)\end{array}$ & $\begin{array}{l}40(75.5) \\
13(24.5)\end{array}$ & 0.414 \\
\hline
\end{tabular}

Abbreviation: ECOG, Eastern Cooperative Oncology Group.

severity of symptoms was outlined in Table S1. The main AEs were anorexia, somnolence, and constipation. The olanzapine group had higher rates of somnolence $(47.5 \%$ : $15.1 \%, \mathrm{p}=0.001)$ and dizziness $(30.0 \%: 9.4 \%, \mathrm{p}=0.011)$.

Table 2 Complete Response According to Study Group

\begin{tabular}{|l|l|l|l|}
\hline Variables & $\begin{array}{l}\text { Olanzapine } \\
(\mathbf{n = 4 0 )}\end{array}$ & $\begin{array}{l}\text { Control } \\
(\mathbf{n = 5 3 )}\end{array}$ & P-value \\
\hline $\begin{array}{l}\text { 0-24 Hours after } \\
\text { chemotherapy } \\
\text { Yes } \\
\text { No }\end{array}$ & $33(85.0)$ & $39(73.6)$ & 0.309 \\
\hline $\begin{array}{l}24-120 \text { Hours after } \\
\text { chemotherapy } \\
\text { Yes }\end{array}$ & $30(75.0)$ & $29(54.7)$ & \\
No & $10(25.0)$ & $24(45.3)$ & \\
\hline $\begin{array}{l}\text { 0-I20 Hours after } \\
\text { chemotherapy } \\
\text { Yes }\end{array}$ & $28(70.0)$ & $25(47.2)$ & \\
No & $12(30.0)$ & $28(52.8)$ & \\
\hline
\end{tabular}

Conversely, the incidence of insomnia (15.0\%: $41.5 \%$, $\mathrm{p}=0.006)$ and anorexia (57.5\%: 79.2\%, $\mathrm{p}=0.024)$ in the olanzapine group was lower (Table 5).

\section{Discussion}

Chemotherapy is one of the most important treatments for gastrointestinal tumor. More than $50 \%$ of patients need systemic chemotherapy at different stages of the disease, and CINV is one of the most common side effects of chemotherapy.

The severity of CINV depends mainly on the vomiting potential of the chemotherapy regimen. Generally, antitumor drugs can be classified into high, moderate, low, and mild vomiting risk levels, with the incidence for vomiting, if not treated with prophylactics, being $>90 \%, 30 \% \sim 90 \%, 10 \%$ $\sim 30 \%$ and $<10 \%$, respectively. According to NCCN and Chinese guidelines on CINV, 5-HT3 RA, dexamethasone, and NK1 RA, a triple antiemetic regimen is recommended before an HEC regimen chemotherapy to prevent nausea and vomiting, and 5-HT3 RA combined with dexamethasone is recommended for the prevention of nausea and vomiting caused by the MEC regimen. Clinical data also suggest that the MEC regimen is highly heterogeneous (30\% 90\%) compared to the HEC regimen. ${ }^{18}$

In the chemotherapy of gastrointestinal tumors, oxaliplatin or irinotecan combined with 5-FU is the most common regimen and, according to guidelines, an MEC. Recent studies have shown that for patients receiving chemotherapy with non-AC MEC regimens, some CINVs are uncontrollable despite standard dual antiemetic prophylaxis. A study in Japan showed that $48 \%$ of patients who received MEC regimens such as carboplatin developed nausea even with 5-HT3 RA and dexamethasone for prophylaxis. ${ }^{19}$ The MOSAIC study also found that patients with colorectal cancer treated with oxaliplatin combined with 5-FU had a significantly higher incidence of grade $3 /$ $4 \mathrm{CINV}$ than those treated with 5-FU monotherapy, even with a standard preventive regimen. The incidence of grade $1 / 2$ CINV in the combination group was also significantly higher (41.4\%: $22.6 \%) .{ }^{20}$ Another prospective trial found that in patients with colorectal cancer receiving FOLFOX chemotherapy, standard prophylaxis prevented $90 \%$ of CINV in the first $24 \mathrm{~h}$, but after 5 days of followup, this value decreased to $54 \%$ due to delayed nausea and vomiting. ${ }^{21}$ A number of studies have shown that 5-HT3 RA provides better control of CINV in the acute phase, but it is less effective in preventing CINV in the delayed phase. ${ }^{22}$ Because of the poor control of delayed vomiting 


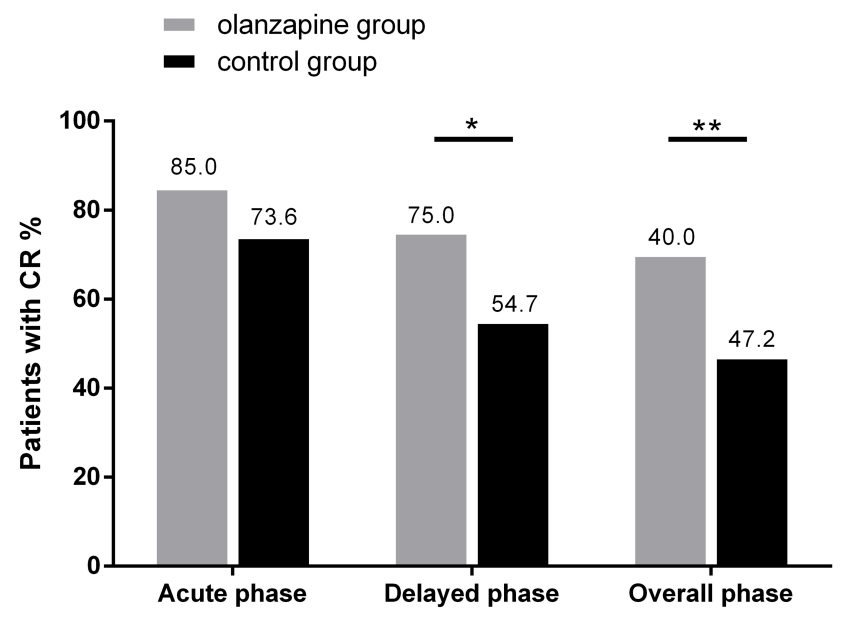

Figure 2

caused by MEC in the dual drug regimen, for this group of patients, we need to explore more drug combinations to better control delayed nausea and vomiting.

A multicenter, randomized, open, Phase III study in Japan compared the efficacy of the NK1 RA triple and standard dual drug regimens in patients with colorectal cancer who received oxaliplatin chemotherapy. The results showed that the proportions of patients with no vomiting in overall and delayed phase in the aprepitant group were significantly higher than that in the control group $(95.7 \%$ vs $83.695 .7 \%$ vs $84.7 \%$, respectively). ${ }^{23}$ Subsequent studies with small sample sizes also demonstrated that for MEC regimens containing carboplatin, oxaliplatin, or irinotecan, the aprepitant triple regimen can better control CINV than the standard dual regimen. ${ }^{24,25}$ However, because aprepitant has not been

Table 3 Other Secondary End Points Analyzed According to the Study Group

\begin{tabular}{|l|l|l|l|}
\hline Variables & $\begin{array}{l}\text { Olanzapine } \\
(\mathbf{n}=\mathbf{4 0})\end{array}$ & $\begin{array}{l}\text { Control } \\
(\mathbf{n}=53)\end{array}$ & P-value \\
\hline $\begin{array}{l}\text { No nausea in the overall } \\
\text { phase } \\
\text { Yes }\end{array}$ & $22(55.0)$ & $19(35.8)$ & \\
No & $18(45.0)$ & $34(64.2)$ & \\
\hline $\begin{array}{l}\text { No significant nausea in } \\
\text { the overall phase }\end{array}$ & & & 0.066 \\
Yes & $26(65.0)$ & $24(45.3)$ & \\
No & $14(35.0)$ & $29(54.7)$ & \\
\hline $\begin{array}{l}\text { Complete control } \\
\text { Yes }\end{array}$ & $25(62.5)$ & $21(39.6)$ & \\
No & $15(37.5)$ & $32(60.4)$ & \\
\hline
\end{tabular}

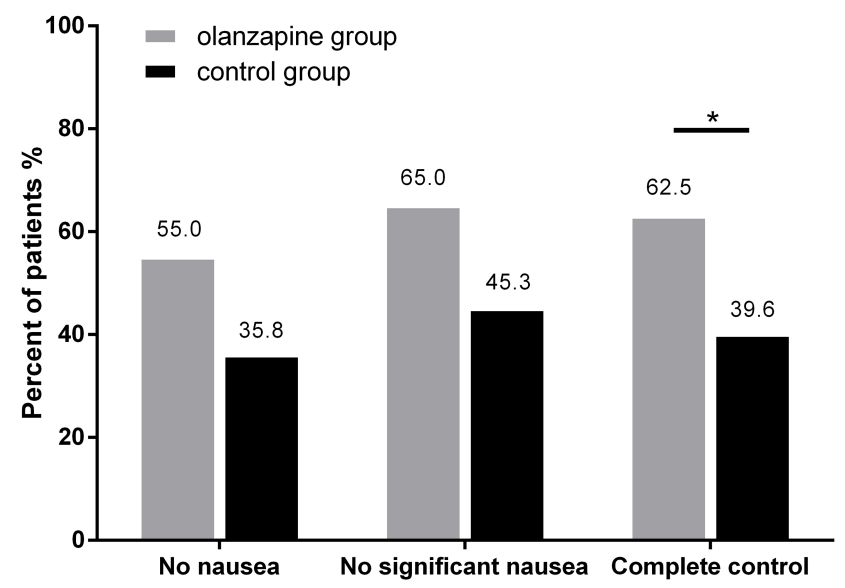

Figure 3

incorporated into the Chinese national health insurance program yet, the triple regimen increases the economic burden of the patients; this issue is the main reason why most patients have not chosen this option. In a recent phase III study, olanzapine and aprepitant were equally effective in preventing CINV in patients receiving HEC chemotherapy, with olanzapine exhibiting better efficacy for delayed vomiting. ${ }^{26}$ Tan et al reported a trial that showed that olanzapine is more effective in the control of delayed vomiting and nausea than 5-HT3 RA. ${ }^{27}$ At present, the efficacy of olanzapine in patients receiving MEC remains poorly studied. In a small size randomized trial, the addition of olanzapine to standard treatment reduced the incidence of CINV and improved the QoL of patients receiving HEC or MEC. ${ }^{28}$ However, in this trial, each group enrolled less than 10

Table 4 FLIE Questionnaire

\begin{tabular}{|c|c|c|c|}
\hline Variables & $\begin{array}{l}\text { Olanzapine } \\
(n=40)\end{array}$ & $\begin{array}{l}\text { Control } \\
(n=53)\end{array}$ & P-value \\
\hline $\begin{array}{l}\text { FLIE total score } \\
(\text { Mean } \pm S D)\end{array}$ & $113.9 \pm 21.5$ & $103.1 \pm 25.0$ & 0.032 \\
\hline $\begin{array}{l}\text { Nausea domain } \\
(\text { Mean } \pm S D)\end{array}$ & $55.9 \pm 11.5$ & $49.8 \pm 13.4$ & 0.023 \\
\hline $\begin{array}{l}\text { Vomiting domain } \\
\text { (Mean } \pm S D)\end{array}$ & $58.1 \pm 10.2$ & $53.4 \pm 11.8$ & 0.049 \\
\hline $\begin{array}{l}\text { Impact on daily life, } \\
\mathrm{n}(\%)\end{array}$ & & & 0.011 \\
\hline Yes & $10(25.0)$ & 27 (50.9) & \\
\hline No & $30(75.0)$ & $26(49.1)$ & \\
\hline
\end{tabular}

Abbreviations: FLIE, the Functional Living Index-Emesis; SD, standard deviation. 
Table 5 Adverse Events During the Study Period

\begin{tabular}{|l|l|l|l|}
\hline Variables & Olanzapine (n=40) & Control (n=53) & P-value \\
\hline Weight loss & $4(10.0)$ & $4(7.5)$ & 0.722 \\
Insomnia & $6(15.0)$ & $22(41.5)$ & 0.006 \\
Anorexia & $23(57.5)$ & $42(79.2)$ & 0.024 \\
Somnolence & $19(47.5)$ & $8(15.1)$ & 0.001 \\
Dizziness & $12(30.0)$ & $5(9.4)$ & 0.011 \\
Constipation & $25(62.5)$ & $32(60.4)$ & 0.835 \\
ALT & $5(12.5)$ & $9(17.0)$ & 0.550 \\
elevation & & & \\
\hline
\end{tabular}

Abbreviation: ALT, alanine transaminase.

patients undergoing MEC. Recently, Jeon et al conducted a randomized, placebo-controlled, small-sample study to evaluate the efficacy of olanzapine combined with palonosetron and dexamethasone in patients receiving MEC. ${ }^{29}$ However, the results revealed that olanzapine in addition to palonosetron and dexamethasone could not significantly improve the CR rate for acute, delayed, and overall phase. The current study retrospectively observed the efficacy and safety of olanzapine in patients receiving MEC. Our results show that combining olanzapine with the conventional antiemetic regimen (5-HT3 RA + dexamethasone) resulted in a higher CINV CR rate compared to the control treatment at all stages, especially in the delayed phase, which is statistically significant. The proportion of nausea patients with no significant nausea in the whole period was significantly better than that of the control group. To our knowledge, this study had the largest sample size of this nature to date, which revealed that the olanzapine triple regimen is effective for patients with gastrointestinal tumor receiving MEC. Although the results cannot be generalized over the entire MEC population, it provide a basis for further clinical research.

Heterogeneity among chemotherapy regimens can affect the control of CINV, and the differences among

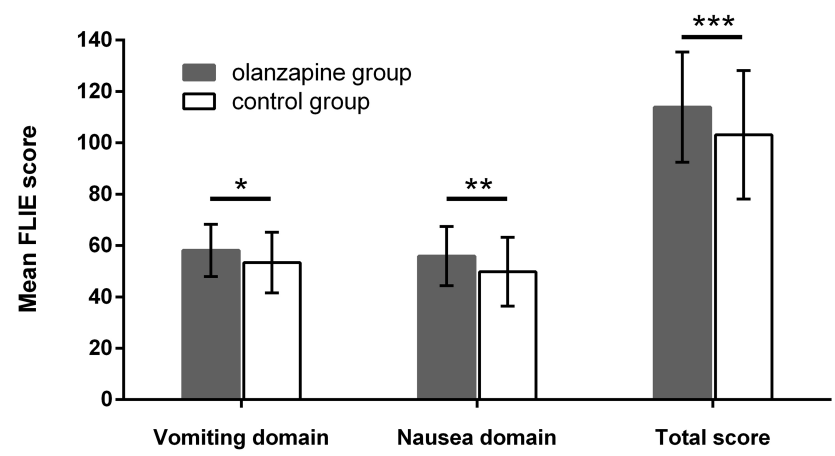

Figure 4 individuals should not be ignored. A study in Japan analyzed pooled data from three studies on the antiemetic effect of palonosetron. The analysis included 1549 chemotherapy-naïve patients in two Phase II trials and a phase III trial. They found that women, age $<55$ years, nonhabitual drinkers, and non-smokers were associated with acute treatment failure. The number of risk factors was significantly associated with CINV in the acute and delayed phases. The more the risk factors, the higher the risk for CINV; additionally, young women with little or no alcohol consumption exhibited the highest incidence of CINV. ${ }^{30}$ Subsequent studies have also found that previous chemotherapy vomiting, early pregnancy response, motion sickness history, and mental state are also associated with CINV. $^{31}$ Therefore, this study recruited patients with digestive tract cancer who exhibited high-risk factors and who received MEC chemotherapy, treated them with the olanzapine triple antiemetic regimen, and showed good antiemetic effects, indicating that this group of people benefited greatly from olanzapine. The CINV CR rate and $\mathrm{CC}$ rate in the olanzapine group and the control group were lower than those reported in most clinical studies, indicating that the control of CINV was more difficult in this subset of CINV high-risk patients. Future research should give more attention to treatment intensification and multi-drug combination in this group.

The results of this study also showed that the incidence of adverse reactions in the olanzapine group was lower, mainly consisting of dizziness, lethargy, and constipation. The symptoms were controllable, and the patients were well tolerant. This study utilized the FLIE questionnaire to assess the impact of CINV on QoL; it was found that the olanzapine group was significantly better than the control group. For patients receiving chemotherapy, the decline in QoL caused by CINV is the most important cause for patients discontinuing treatment. ${ }^{32}$ Studies have shown that even in patients with mild nausea, food intake is reduced by $300-500 \mathrm{kcal}$ compared with patients without nausea. ${ }^{33}$ The improvement in QoL in this study can be attributed to the effective control of CINV and the pharmacological properties of olanzapine. As a psychiatric drug, olanzapine exhibits increased adverse effects such as increased body weight, appetite, and sedation. In cancer patients, the incidence of anxiety and depression is high, reaching $7.6 \% \sim 49 \% .{ }^{34}$ The number of patients with sleep disorders is more than $31 \%$ to $57 \% .^{35}$ Therefore, the adverse reactions of olanzapine are, in fact, beneficial for cancer patients, improving the treatment response rate, as 
well as QoL. These results were further confirmed by the fact that the proportion of patients with insomnia and appetite loss in the olanzapine group was decreased significantly compared with the control group.

everal limitations should be considered in the present study. First, it was a retrospective case-control study with a relatively small number of patients, Treatment and selection bias is inevitable. In fact, doctors make therapeutic decisions whether to add olanzapine or not based on the judgement of individual CINV risk and patient-clinician conversation. It is likely that patients received the olanzapine-containing triple antiemetic regimen tended to have more risk factors for CINV. However, the results still showed better control of CINV in patients with olanzapine-containing regimen. Therefore, in light of these, we think that our result is plausible. But the conclusions need to be verified in larger prospective studies. Second, since patients with gastrointestinal tumor were relatively young and common among women in the two institutions, we only focus on the population harbor three CINV high-risk factors. In addition, there are other factors that may be important but have not been included in the present study, such as history of motion sickness or pregnancy-associated morning sickness, symptoms of anxiety or expectation. Therefore, it is unknown whether these findings are applicable to other high-risk patients or the whole population of patients receiving MEC. Further multicenter prospective studies and large clinical investigations should be conducted to explore the effect of olanzapine in these patients. Third, the retrospective nature of this study and the limited information available from the medical records limited this study's ability to report on some commonly used endpoints in antiemetic clinical trials such as acute and delay nausea.

\section{Conclusion}

The data provided in this double-center retrospective and non-randomized observational study indicate that antiemetic prophylaxis with the triple regimen of olanzapine combined with 5-HT3 RA and dexamethasone was safe and effective as CINV prophylaxis in gastrointestinal tumor patients with high-risk factors for CINV who were receiving $\mathrm{MEC}$. The olanzapine-containing triple antiemetic regimen, compared with a tropisetron/dexamethasone regimen, exhibits better efficacy for the prevention of delayed and overall emesis and improvement of the nausea control rate. Furthermore, the addition of olanzapine reduced the negative impact of CINV on the QoL of patients. The adverse effects or symptoms were tolerable in the two groups. Further randomized and controlled studies with a larger sample size are required to confirm the efficacy of olanzapine in this clinical setting.

\section{Ethics and Consent Statement}

This study was approved by Ethics Committee of Peking University Shenzhen Hospital. And all the protocol used in the present study was approved by the Institutional Review Boards of all participating centers. Moreover, all these procedures were performed in accordance with the ethical standards established in the Declaration of Helsinki. All patients provided written informed consent before starting the study.

\section{Acknowledgments}

The authors would like to thank the patients, nurses, and clinicians for their participation in this study. This work was supported by Natural Science Foundation of Guangdong Grants (2016A030313381; 2016A030310242); The National Natural Science Foundation project of China (81602489); Shenzhen Sanming Project (SZSM201612041); Shenzhen Science and Technology Innovation Commission Project (GJHZ20180420180754917, ZDSYS20190902092855097).

\section{Disclosure}

The authors report no conflicts of interest in this work.

\section{References}

1. Wiser W, Berger A. Practical management of chemotherapy induced nausea and vomiting. Oncology. 2005;19(5):637-645.

2. Osoba D, Zee B, Warr D, et al. Effect of postchemotherapy nausea and vomiting on health-related quality of life. Support Care Cancer. 1997;5(4):307-313. doi:10.1007/s005200050078

3. Ingle RJ, Burish TG, Wallston KA. Conditionability of cancer chem otherapy patients. Oncol Nurs Forum. 1984;11(4):97-102.

4. Richardson JL, Marks G, Levine A. The influence of symptoms of disease and side effects of treatment on compliance with cancer therapy. J Clin Oncol. 1988;6(11):1746-1752. doi:10.1200/JCO.1988.6.11.1746

5. Herrstedt J. Antiemetics: an update and the MASCC guidelines applied in clinical practice. Nat Clin Pract Oncol. 2008;5(1):32-43. doi:10.1038/ncponc1021

6. Hesketh PJ, Grunberg SM, Herrstedt J, et al. Combined data from two phase trials of the NK1 antagonist aprepitant plus a 5HT3 antagonist and a corticosteroid for prevention of chemotherapy-induced nausea and vomiting: effect of gender on treatment response. Support Care Cancer. 2006;14(4):354-360. doi:10.1007/s00520-005-0914-4

7. Hesketh PJ, Bohlke K, Lyman GH, et al. Antiemetics: American Society of Clinical Oncology focused guideline update. $J$ Clin Oncol. 2016;34(4):381-386. doi:10.1200/JCO.2015.64.3635

8. Herrstedt J, Roila F, Warr D, et al. 2016 Updated MASCC/ESMO consensus recommendations: prevention of nausea and vomiting following high emetic risk chemotherapy. Support Care Cancer. 2017;25 (1):277-288. doi:10.1007/s00520-016-3313-0

9. Jordan K, Gralla R, Jahn F, et al. International antiemetic guidelines on chemotherapy induced nausea and vomiting (CINV): content and implementation in daily routine practice. Eur $J$ Pharmacol. 2014;722:197-202. doi:10.1016/j.ejphar.2013.09.073 
10. Hesketh PJ, Kris MG, Basch E, et al. Antiemetics: American Society of Clinical Oncology clinical practice guideline update. J Clin Oncol. 2017;35(28):3240-3261. doi:10.1200/JCO.2017.74.4789

11. Roila F, Molassiotis A, Herrstedt J, et al. 2016 MASCC and ESMO guideline update for the prevention of chemotherapy- and radiotherapy-induced nausea and vomiting and of nausea and vomiting in advanced cancer patients. Ann Oncol. 2016;27(suppl 5): v119v133. doi:10.1093/annonc/mdw270

12. Tournigand $\mathrm{C}$, André $\mathrm{T}$, Achille E, et al. FOLFIRI followed by FOLFOX6 or the reverse sequence in advanced colorectal cancer: a randomized GERCOR study. J Clin Oncol. 2004;22(2):229-237. doi:10.1200/JCO.2004.05.113

13. Bymaster FP, Falcone JF, Bauzon D, et al. Potent antagonism of 5-HT(3) and 5-HT(6) receptors by olanzapine. Eur J Pharmacol. 2001;430(23):341-349. doi:10.1016/S0014-2999(01)01399-1

14. Srivastava M, Brito-Dellan N, Davis MP, et al. Olanzapine as an antiemetic in refractory nausea and vomiting in advanced cancer J Pain Symptom Manage. 2003;25(6):578-782 . doi:10.1016/S08853924(03)00143-X

15. Natale JJ. Reviewing current and emerging antiemetics for chemotherapy-induced nausea and vomiting prophylaxis. Hosp Pract. 2015;43(4):226-234. doi:10.1080/21548331.2015.1077095

16. Navari RM, Qin R, Ruddy KJ, et al. Olanzapine for the prevention of chemotherapy-induced nausea and vomiting. N Engl J Med. 2016;375 (2):134-142. doi:10.1056/NEJMoa1515725

17. Nakagaki M, Barras M, Curley C, et al. A randomized trial of olanzapine versus palonosetron versus infused ondansetron for the treatment of breakthrough chemotherapy-induced nausea and vomiting in patients undergoing hematopoietic stem cell transplantation. Support Care Cancer. 2017;25(2):607-613. doi:10.1007/s00520-016-3445-2

18. Jordan K, Jahn F, Aapro M. Recent developments in the prevention of chemotherapy-induced nausea and vomiting (CINV): a comprehensive review. Ann Oncol. 2015;26(6):1081-1090. doi:10.1093/annonc/mdv138

19. Momose H, Ide $\mathrm{T}$, Tateishi $\mathrm{K}$, et al. Incidence of chemotherapy-induced nausea and vomiting in patients receiving carboplatin-including chemotherapy. Gan to Kagaku Ryoho. 2013;40(3):355-359.

20. André T, Boni C, Mounedji-Boudiaf L, et al. Oxaliplatin, fluorouracil, and leucovorin as adjuvant treatment for colon cancer. $N$ Engl $J$ Med. 2004;350(23):2343-2351. doi:10.1056/NEJMoa032709

21. Hesketh PJ, Sanz-Altamira P, Bushey J, et al. Prospective evaluation of the incidence of delayed nausea and vomiting in patients with colorectal cancer receiving oxaliplatin-based chemotherapy. Support Care Cancer. 2012;20(5):1043-1047. doi:10.1007/s00520011-1180-2

22. Hickok JT, Roscoe JA, Morrow GR, et al. 5-Hydroxytryptamine receptor antagonists versus prochlorp erazine for control of delayed nausea caused by doxorubicin: a URCC CCOP randomised controlled trial. Lancet Oncol. 2015;6(10):765-772. doi:10.1016/S14702045(05)70325-9

23. Nishimura J, Satoh T, Fukunaga M, et al. Combination antiemetic therapy with aprepitant/fosaprepitant in patients with colorectal cancer receiving oxaliplatin-based chemotherapy (SENRI trial) a multicentre, randomised, controlled Phase 3 trial. Eur J Cancer. 2015;51(10):1274-1282. doi:10.1016/j.ejca.2015.03.024

Cancer Management and Research

Publish your work in this journal

Cancer Management and Research is an international, peer-reviewed open access journal focusing on cancer research and the optimal use of preventative and integrated treatment interventions to achieve improved outcomes, enhanced survival and quality of life for the cancer patient.
24. Toda H, Kawazoe H, Yano A, et al. Antiemetic effectiveness and cost-saving of aprepitant plus granisetron is superior to palonosetron in gastrointestinal cancer patients who received moderately emetogenic chemotherapy. J Cancer. 2017;8(8):1371-1377. doi:10.7150/jca.17102

25. Aridome K, Mori SI, Baba K, et al. A phase ii, randomized study of aprepitant in the prevention of chemotherapy-induced nausea and vomiting associated with moderately emetogenic chemotherapies in colorectal cancer patients. Mol Clin Oncol. 2016;4(3):393-398. doi: $10.3892 /$ mco. 2015.724

26. Navari RM, Gray SE, Kerr AC. Olanzapine versus aprepitant for the prevention of chemotherapy-induced nausea and vomiting: a randomized phase III trial. J Support Oncol. 2011;9(5):188-195. doi:10.1016/j.suponc.2011.05.002

27. Tan L, Liu J, Liu X, et al. Clinical research of Olanzapine for prevention of chemotherapy-induced nausea and vomiting. $J \operatorname{Exp}$ Clin Cancer Res. 2009;28(1):131. doi:10.1186/1756-9966-28-131

28. Mizukami N, Yamauchi M, Koike K, et al. Olanzapine for the prevention of chemotherapy-induced nausea and vomiting in patients receiving highly or moderately emetogenic chemotherapy: a randomized, double-blind, placebo-controlled study. J Pain Symptom Manage. 2014;47(3):542-550. doi:10.1016/j.jpainsymman.2013.05.003

29. Jeon SY, Han HS, Bae WK, et al. A randomized, double-blind, placebo-controlled study of the safety and efficacy of olanzapine for the prevention of chemotherapy-induced nausea and vomiting in patients receiving moderately emetogenic chemotherapy: results of the Korean South West Oncology Group (KSWOG) study. Cancer Res Treat. 2019;51(1):90-97. doi:10.4143/crt.2017.577

30. Sekine I, Segawa Y, Kubota K, et al. Risk factors of chemotherapy-induced nausea and vomiting: index for personalized antiemetic prophylaxis. Cancer Sci. 2013;104(6):711-717. doi:10.1111/cas.12146

31. Warr D. Prognostic factors for chemotherapy induced nausea and vomiting. Eur J Pharmacol. 2014;722:192-196. doi:10.1016/j. ejphar.2013.10.015

32. Sun CC, Bodurka DC, Weaver CB, et al. Rankings and symptom assessments of side effects from chemotherapy: insights from experienced patients with ovarian cancer. Support Care Cancer. 2005;13 (4):219-227. doi:10.1007/s00520-004-0710-6

33. Lorusso V, Spedicato A, Petrucelli L, et al. Single dose of palonosetron plus dexamethasone to control nausea, vomiting and to warrant an adequate food intake in patients treated with highly emetogenic chemotherapy (HEC). Preliminary Results Support Care Cancer. 2009;17(12):1469-1473. doi:10.1007/s00520-009-0611-9

34. Yi JC, Syrjala KL. Anxiety and depression in cancer survivors. Med Clin North Am. 2017;101(6):1099-1113. doi:10.1016/j.mcna.2017.06.005

35. Otte JL, Carpenter JS, Manchanda S, et al. Systematic review of sleep disorders in cancer patients: can the prevalence of sleep disorders be ascertained? Cancer Med. 2015;4(2):183-200. doi:10.1002/ cam4.356

The manuscript management system is completely online and includes a very quick and fair peer-review system, which is all easy to use. Visit http://www.dovepress.com/testimonials.php to read real quotes from published authors. 